\title{
Towards a Software Tool Supporting Urban Decision Makers in Locating and Sizing the Household Garbage Accumulation Points Within Cities
}

\author{
Paolino Di Felice \\ Department of Industrial and Information Engineering \& Economics, University of L'Aquila, L'Aquila, Italy
}

\begin{abstract}
Locating and sizing garbage bins for the separate accumulation of household solid waste within urban areas is of primary interest for the local administrations that so far lack adequate IT support. The paper highlights the versatility of a method for solving such a problem, which involves both standard and geographic data. Implementation of the proposal, centered around a spatial database, goes in the direction of developing a supporting software tool to the officials responsible for the management of municipal solid waste. They are offered a dual-mode display of the results: one tabular (the standard format featured by relational databases) and the other based on the metaphor of geographic maps, the latter being particularly useful in capitalizing on the spatial component of the problem.
\end{abstract}

Keywords: solid waste, garbage accumulation point, garbage bin, algorithm, integrated spatial and descriptive data, SQL, decision support system

\section{Introduction}

"Managing solid waste (SW) well and affordably is one of the key challenges of the $21 \mathrm{st}$ century, and one of the key responsibilities of a city government" (UN-HABITAT, 2010). The quality of waste management services is a good indicator of a city's governance. The way in which waste is produced and discarded gives us a key insight into how people live. In fact, if a city is dirty, the local administration may be considered ineffective or its residents may be accused of littering.

The major types of urban SW are residential and commercial. Households are the highest producers of municipal waste (EEA, 2013).
Damghani et al. (2008) report that in Tehran, the capital of Iran, the contribution of the household SW to the total municipal SW is around $62 \%$. A similar estimation about the Americans' production of residential SW is reported in (US EPA, 2010).

Tchobanoglous et al. (1993) categorize the activities of a municipal SW management system as a six steps procedure: waste generation; handling, separation, storage, and processing at the source (in the following briefly called $a c$ cumulation); collection; transfer and transport; separation, processing and transformation; and disposal.

In Italy, nowadays, SW is accumulated using two complementary methods. For many years, the municipalities have spread on the major crossroads in the towns large-sized garbage bins (GBs). Daily, households put their SW in these public containers, while, cyclically, municipality-owned machines take away the SW from them. A more recent method consists of providing families with much smaller GBs and municipal workers collect the garbage door-to-door. So far, the first method covers the largest waste disposal production. That is why this study refers to such a scenario.

From the citizens' point of view, SW accumulation and collection are among the most visible urban services. If properly implemented, they contribute:

- to keep modern towns clean; 
- to develop the culture of urban cleanliness;

- to protect municipal workers dealing with the collection and transportation of infectious waste materials (Miyazaki et al., 2007);

- to protect the health of pets (they regularly visit GBs looking for food residues, with the tangible risk of getting sick) and, therefore, they contribute to protect the health of residents, too;

- to keep high the market value of the apartments in the area;

- to get high residents' satisfaction. In fact, the effectiveness of garbage accumulation and collection is a variable largely used in the studies investigating the satisfaction of individuals living in the urban areas, e.g., (Felix \& Garcia-Vega, 2012).

Unfortunately, spatial distribution of the garbage accumulation points (GAPs) inside towns does not take the needs of local residents into account in terms of the quantities of waste produced and the distance from their dwelling (Parrot et al., 2009). That induces the following two side effects: a) often the GBs are full and, in those cases, the citizens' decision is to leave the bags of garbage outside the GBs; b) when the distance to the closest GB is long, households tend to dispose the domestic waste in open areas. Similar concerns about inconvenient location of the GAPs are expressed by Zia \& Devadas (2008).

In our opinion, the only way to overcome those limits is to provide local administrators with an ad hoc software tool assisting them during the GBs allocation phase. This work was meant to give a contribution in the direction of developing a software tool of this type.
The tool has to be developed on top of a general method that solves "correctly" what in the remainder of the paper we call the solid waste accumulation problem (SWAP). Here, correctly means to come to a location of the GAPs in the urban territory, linked to the distance from the house of the citizens; moreover, the number of bins per GAP has to be adapted to the amount of waste "locally" produced by the citizens. Doing so, both drawbacks mentioned above should disappear.

\subsection{Related Work}

A huge amount of research has been done about facility location problems in the field of operational research; for a survey see (ReVelle \& Eiselt, 2005). However, as remarked by Ghiani et al. (2012), contrarily to other location problems in the context of urban waste management, the SWAP has received little attention in the literature and only quite recently.

The unique papers pertinent to the topic are listed and compared in Table 1 . The second column in Table 1 tells us that all the papers solve the problem of locating the GAPs in the urban territory to be served. Their common objective is to minimize the number of GAPs in order to reduce: a) the initial cost of buying the GBs, b) the collection time, and, finally c) the negative visual impact caused by the presence of the GBs near residential buildings.

The third column shows that only the last three papers also compute the sizing of GBs inside each GAP, while the first two do not.

The fourth column tells us about the way those papers take into account the distance between the dwellings and about what in this study we

\begin{tabular}{|c|c|c|c|c|}
\cline { 2 - 5 } \multicolumn{1}{c|}{} & Locating of GAPs & Sizing of GBs & Dwelling-GAP distance & Collection \\
\hline (Badran \& El-Haggar, 2006) & Yes & No & No & Unsorted waste \\
\hline (Bautista \& Pereira, 2006) & Yes & No & Yes (maximum distance) & Unsorted waste \\
\hline (Tralhão et al., 2010) & Yes & Yes & Yes (average distance) & Sorted waste \\
\hline (Ghiani et al., 2012) & Yes & Yes & Yes (maximum distance) & Unsorted waste \\
\hline Present contribution & Yes & Yes & Yes (maximum distance) & Sorted waste \\
\hline
\end{tabular}

Table 1. The related work. 
call the reference GAP, that is, the GAP closest to the houses. (Badran et al., 2006) ignore the issue, while (Tralhão et al., 2010) minimize the average distance from dwellings to the reference GAP. The remaining three papers take the distance dwelling-(reference)GAP within a fixed maximum threshold. It is fundamental to guarantee that each family has, at a "suitable" distance, a GAP and this assures an adequate quality of the service to all residents in the area. Relevance of this issue has been pointed out clearly in numerous studies about the "quality of life", e.g., (Felix \& Garcia-Vega, 2012). Quality of the service of accumulation and collection of the household waste is perceived as relevant by citizens for two reasons. Because they support this service by paying taxes and, therefore, it is quite obvious that they have expectations reqarding the quality of the returned service, and, moreover, because of the growing public concern about environmental preservation.

The last column in Table 1 specifies whether the SW is accumulated/collected in a sorted or unsorted way.

Ghiani et al. (2012) give two alternative solutions of the SWAP: the first adopts an integer programming model, while the second adopts a two-phases heuristic approach. They introduced the latter approach because the complexity of the integer programming model makes it very difficult to be solved optimally within a reasonable time by means of a general purpose solver. The method we propose in this paper bears a likeness to the heuristic approach by Ghiani et al. (2012), with which it shares also the motivation of finding a good solution of the SWAP in a short computational time.

Ghiani et al. (2012) start from a given set of GAPs located at a known position inside the city and return the minimum number of reference collection sites to be allocated, chosen among the initial candidates. In our approach, on the contrary, the reference GAPs may be located at any point of the city roads (same assumption as in Bautista \& Pereira, 2006) and their number and position result from the elaboration of a method determined by the "urban geography" of the dwellings to be served.

The remainder of the paper is structured as follows. Section 2 defines the SWAP inside modern towns and lists our notations. Section 3 focuses on two algorithms that together provide a general solution of the SWAP by integrating spatial and descriptive data. The first algorithm determines the location of the GAPs in the urban territory to be served, while the second allocates the number of bins to each GAP. The position of the GAPs is set by taking into account the distance from the house of the citizens, while the number of bins is adequate to the amount of litter produced "locally" on daily basis. Such two-phases method has been introduced in (Di Felice, 2013). The algorithms strictly refer to the accumulation of the residential SW, but they can be easily adapted to other types of litter (e.g., the commercial SW). Section 4 touches on a way to implement the two algorithms in terms of open source software, while Section 5 reports about a pilot study applied to a political district of the town of L'Aquila (central Italy), whose results are presented and discussed in Section 6. Those three sections show a simple and effective way to implement the theory using the technology of the spatial database management systems (SDBMSs), and, more important, the versatility of the proposed solution from the point of view of those responsible for municipal SW management who, in fact, is offered a dual-mode display of the results: one tabular (typical of relational databases) and the other based on geographical maps, this latter particularly useful to capitalize on the spatial component of the SWAP. Together, these two operational modes provide a very effective assistance to decision makers. Section 7 focuses on the flexibility of the first algorithm in the allocation of dwellings to the GAPs and on the positive effects of such a feature. Section 8 lists a few SQL pattern queries that make explicit the analysis on demand dimension embedded in the SDBMS-centric implementation we carried out. In fact, by querying the spatial database (SDB), it is possible to extract a lot of extra information from the SDB not easily obtainable in any other way. Section 9 ends the paper.

\section{The Solid Waste Accumulation Problem}

Mathematically, the SWAP can be modeled as a bipartite directed graph G(V1UV2, A), where $\mathrm{A}=\mathrm{V} 1 \mathrm{xV} 2$; the vertices in $\mathrm{V} 1$ represent the dwellings (i.e., the waste generation sources) 
and V2 represent the GAPs. To each arc a numerical value $\left(\right.$ dist $\left._{\mathrm{ij}}\right)$ can be associated, representing the distance between dwelling $i$ and its potential reference GAP $(j)$. Ghiani et al. (2012) start from a given set of GAPs located at known position inside the city, therefore they have V1, V2, and dist $t_{\mathrm{ij}}$ as inputs. Contrarily, we ignore the geographical position of the vertices in V1 (and hence the values dist $t_{\mathrm{ij}}$ ), because, as already noted, in our case the GAPs may be located at any point of the city roads.

At a less abstract level, the SWAP inside modern towns can be formulated as follows: given the set of houses and public roads (the spatial data) being a part of an urban area (Figure 1a), the goal is to compute the location of the GAPs in the area as well as sizing the number of bins. Further relevant data of the problem (they all together give rise to the descriptive data) relate to the type of waste to be stored in the GAPs, capacity of the GBs, the frequency of emptying the GBs of various types, the number of inhabitants in each house in the area to be served, and their per capita daily production of SW.

We solve the SWAP under the following constraints:

a) the GAPs have to be placed on the public roads;

b) every house must have its reference GAP at a distance (measured along the public roads) not greater than a predetermined value;

c) the number of bins for the different types of waste in each GAP must be allocated according to the daily production of household waste of the district.

\section{Notations}

Hereafter we use the following notations:

District is the urban area to be served with GAPs,
$\mathcal{R}=\left\{r_{1}, r_{2}, \ldots, r_{\mathrm{R}}\right\}$ is the set of public roads crossing the District. The generic element of $\mathcal{R}, r_{\mathrm{j}}$, is a triple $<i d$, name, the_geom $>$ whose values, in sequence, denote the unique identifier of the road, its name, and the geometry modeling its shape,

$\mathcal{H}=\left\{h_{1}, h_{2}, \ldots, h_{\mathrm{H}}\right\}$ is the set of houses located inside the District. By house we mean a building having a certain shape on the ground. We do not care about the number of floors composing each building, while the number of people living in it is relevant. The generic element of $\mathcal{H}, h_{\mathrm{j}}$, is defined by the tuple $<i d$, road_id, num, density, the_geom, the_geom_c, the_geom_h $>$ whose values, in sequence, denote the unique identifier of the house, the unique identifier of the reference public road (that is the road that specifies the building's address), the house number, the number of occupants in the dwelling, the geometry of its layout (i.e., a polygon), the simplified geometry of the dwelling (i.e., the centroid of the polygon), the geometry of the projection of the centroid of the dwelling on the reference public road. Figure $1 \mathrm{~b}$ shows the geometry of the layout of the houses, their centroid and the projection of the centroid on the reference road. From here on, when talking about dwellings, we always refer to the projection of their centroid on the reference road; therefore, the scene in Figure 1a is replaced with that in Figure 1c,

$\mathcal{G B}=\left\{\mathrm{gb}_{1}, \mathrm{gb}_{2}, \ldots, \mathrm{gb}_{\mathrm{GB}}\right\}$ is the set of the different types of GBs that are part of each GAP. In the study, we take into account the following five types: glass, plastic, $p a-$ per, organic, and unsorted, but the solution method is general, so it can be adapted to work under different assumptions. The

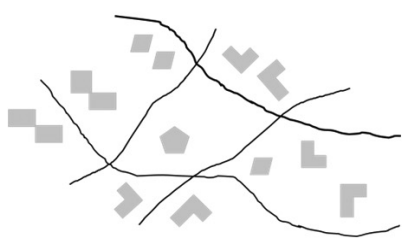

(a)

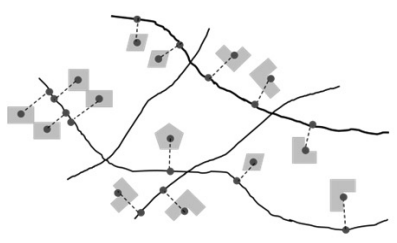

(b)

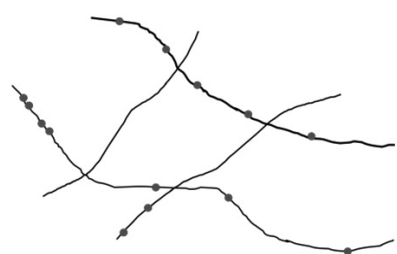

(c)

Figure 1. A scene of roads and houses (a); the original scene plus the centroid of each house and the projection of the centroid on the reference road (b); the roads and the projection of the centroids of the houses on the roads (c). 
generic element of $\mathcal{G B}, g b_{\mathrm{j}}$, is defined by the tuple $<$ id, type, capacity, collection $>$ whose values, in sequence, denote the unique identifier of the GB, its type, its capacity $\left(\mathrm{m}^{3}\right)$, and the frequency of collection (days) from municipality's workers. For example, the tuple $<1$, glass, 1.8, $7>$ specifies that the GB is of type glass, it has id 1 , capacity $1.8 \mathrm{~m}^{3}$, and weekly frequency of collection,

$\mathcal{G} \mathcal{A} \mathcal{P}=\left\{\right.$ gap $_{1}$, gap $_{2}, \ldots$, gap $\left._{\mathrm{GAP}}\right\}$ is the set of GAPs to be dislocated in the District. The generic element of $\mathcal{G A P}$, gap $_{\mathrm{j}}$, is defined by the tuple $<i d$, the_geom, road_id, glass, plastic, paper, organic, unsorted, $r s, h s>$ whose values, in sequence, denote the unique identifier of the GAP, its coordinates, the id of the public road where $g a p_{j}$ is located, the number of GBs for glass, plastic, paper, organic, and unsorted, and, lastly, the total number of residents and houses that the GAP is able to serve,

housesServedBy_aGAP [] is an array of sets data structure having a number of components equal to the cardinality of $\mathcal{G} \mathcal{A P}$. The component housesServedBy_aGAP $[\mathrm{k}]$ stores the (sets of) identifiers of the houses served by the GAP having identifier equal to $k$,

dailyGlass, dailyPlastic, dailyPaper, dailyOrganic, and dailyUnsorted denote, in sequence, the per capita daily generation (in $\mathrm{m}^{3}$ ) of the five different types of SW we refer to in the paper,

Distance denotes the value of the maximum distance between each house and the reference GAP (that is the GAP closest to the house).

All identifiers are positive integers starting from one. Moreover, in the algorithms we are going to present, we use, for brevity, the notation "record_name.field_name" linking a composite variable (record) to one of its parts (field). Therefore, for example, gap. id denotes the identifier of the element $g_{a p}$ of set $\mathcal{G A P}$.

\section{A Strategy to Solve the SWAP}

The solution of the SWAP is obtained in two stages via the algorithms LocatingOfGAPs and SizingOfGAPs to be invoked in sequence. As mentioned in the Introduction, this schema has analogies with the two-phases heuristic approach proposed by Ghiani et al. (2012).

LocatingOfGAPs takes as input the sets $\mathcal{H}$ and $\mathcal{R}$, and the value of $\mathcal{D}$ istance and returns the set $\mathcal{G A P}$ and the data structure housesServedBy aGAP [] to be used as input of the algorithm SizingOfGAPs. After the set $\mathcal{G A P}$ is initialized, the FOR EACH loop is activated. It runs until all the public roads in $\mathcal{R}$ have been visited. The visit of the generic road (Line 3 ) is devoted to locate the position where the GAPs have to

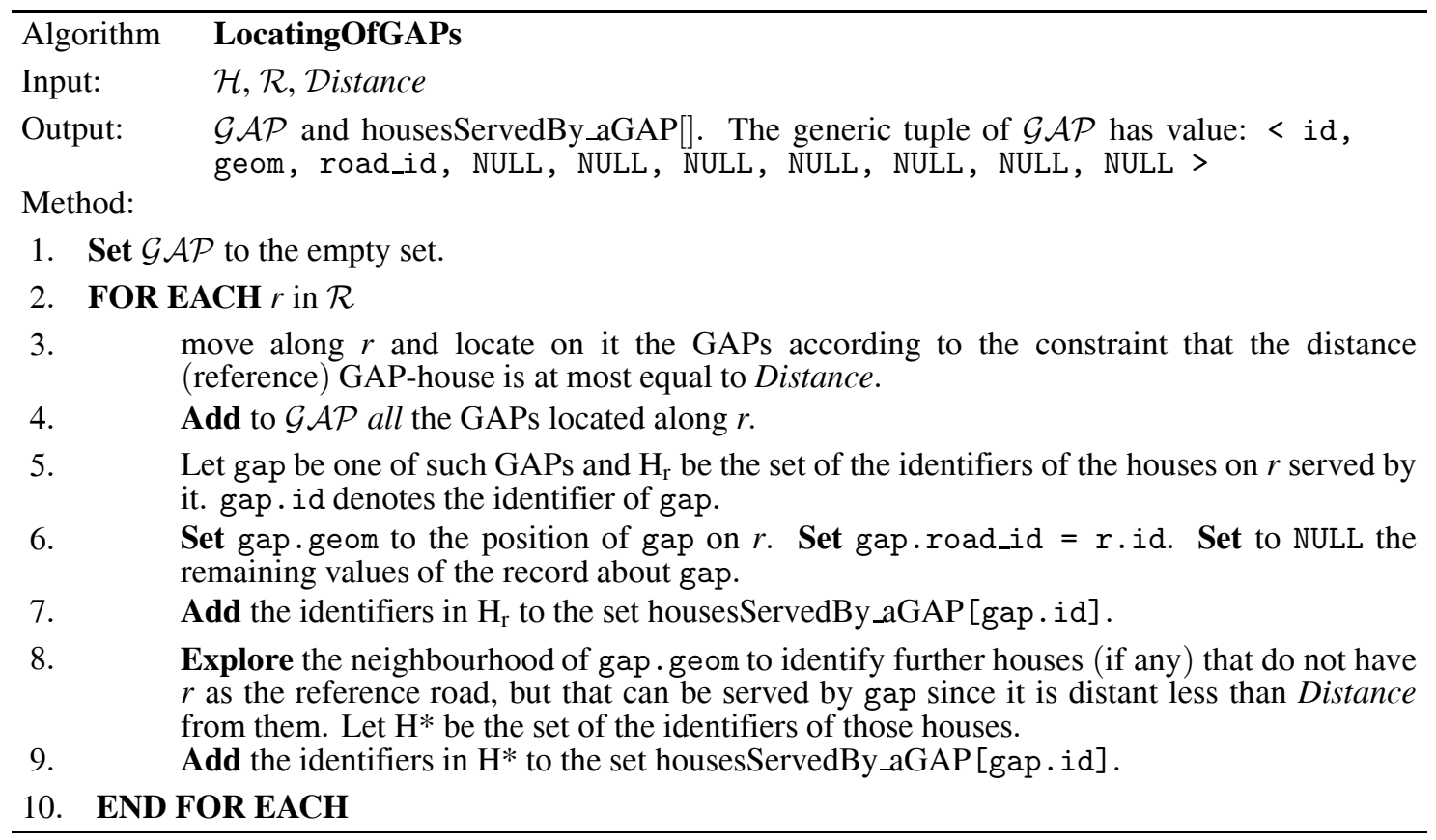




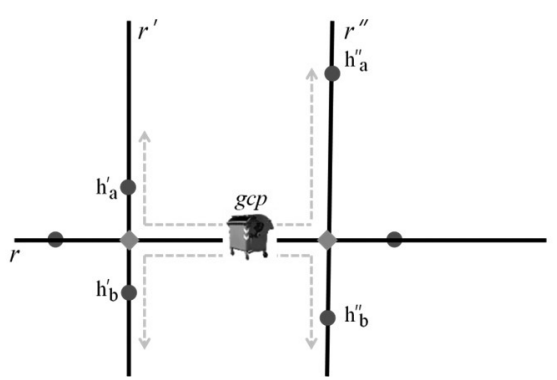

(a)

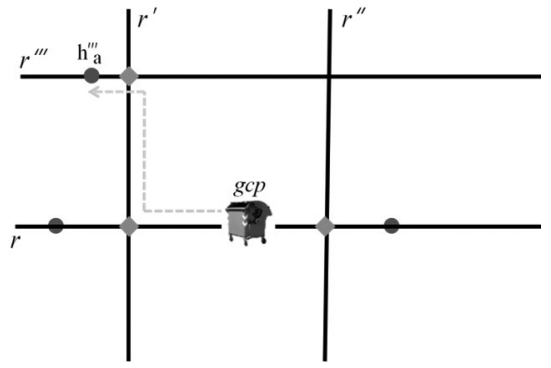

(b)

Figure 2. Dwellings close to the GAP gap (schematically represented by one of the GBs being part of it) located on road $r$, but having as reference road one different from $r$.

be allocated. The decision takes into account the value of the geometry of the projection of the centroid of the dwellings having $r$ as the reference road (the field the _geom_h of Section 2; see also Figure 1c) and the value of Distance. Each time a position is found, the algorithm sets the values of the fields gap.id, gap.geom, and gap.road_id of the record referring to gap, while the remaining fields are set to NULL (Lines 5 and 6). Line 7 copies the identifiers of the dwellings located along $r$ and served by the GAP gap in the set housesServedBy_aGAP [gap . $i d]$. All those dwellings have gap as the reference GAP.

The purpose of Line 8 is to identify further houses (if any) that do not have $r$ as the reference road, but that can be served by gap since it is distant less than Distance from those dwellings. There are two possible situations to be investigated. The first one (Figure 2a) is that of houses that lie on roads that intersect $r$ near to the point where is positioned gap. In the figure, $r$ is intersected by roads $r$ ' and $r$ " at the points marked as diamonds. By hypothesis, $\mathrm{H}^{*}=\left\{\mathrm{h}_{\mathrm{a}}\right.$, $\left.h_{b}, h{ }_{a}, h{ }_{b}\right\}$, i.e., the dwellings $h{ }_{a}, h{ }_{b}, h{ }_{a}$ and $h{ }^{\prime}$ are considered to be served by gap. The second situation (Figure 2b) is about houses that lie on roads different either from $r$ or from the streets that intersect $r$, but still they are close to gap. In Figure $2 b$, by hypothesis, house $h "{ }^{\prime}$, located on the road $r$ ", is distant less than Distance from gap and, therefore, it can be served by such a GAP. In summary, $\mathrm{H}^{*}=\left\{\mathrm{h}_{\mathrm{a}}{ }, \mathrm{h}{ }_{\mathrm{b}}, \mathrm{h}_{\mathrm{a}}{ }^{\text {, }}\right.$, $\mathrm{h}$ " $\mathrm{b}, \mathrm{h}$ "” $\mathrm{a}\}$. Also the dwellings in $\mathrm{H}^{*}$ have gap as the reference GAP. At the end of each iteration, the set housesServedBy_aGAP [gap.id] collects the identifiers of all the roads in $\mathcal{H}$, served by gap, independently of their reference road.

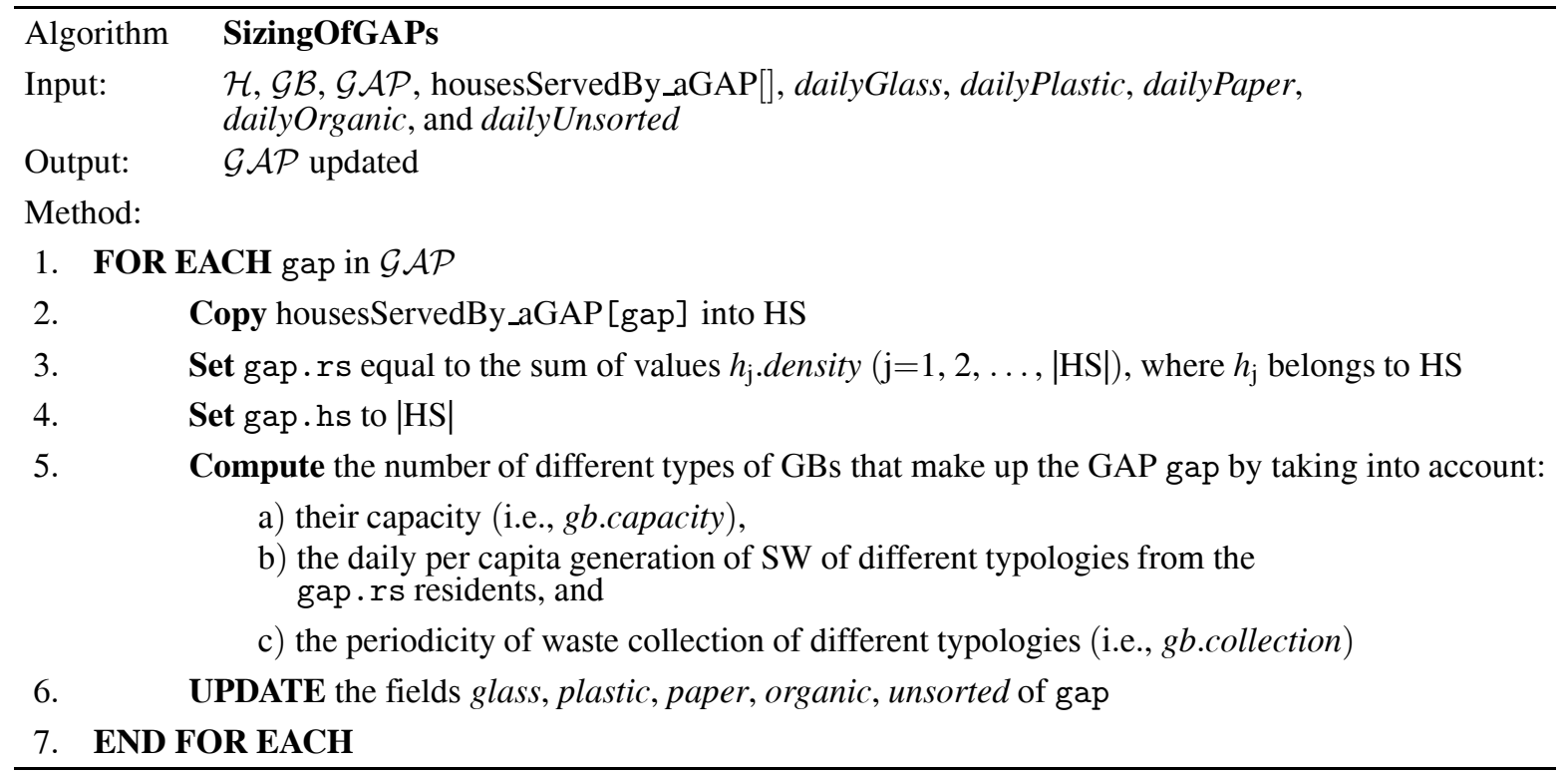


A more detailed version of the algorithm LocatingOfGAPs may be found in (Di Felice, 2013).

SizingOfGAPs updates the values of the records of the set $\mathcal{G A P}$ relatively to the fields left to NULL by LocatingOfGAPs. The algorithm repeats, for each GAP in $\mathcal{G} \mathcal{A} \mathcal{P}$, the following steps. Let gap be the generic GAP. Initially, the content of the set housesServedBy_aGAP [gap], i.e., all the dwellings served by gap, is copied into the variable HS (HouseServed). Then (Line 3), the total number of citizens that gap can serve is calculated. This is done by adding to gap.rs the number of inhabitants in each of the houses present in HS. Line 4 sets the field gap.hs to the value of the number of houses served by gap. The next step (Line 5) computes the number of GBs of the five types taken into account in our study. For example, the number of GBs for the glass is calculated as follows:

$$
\begin{gathered}
\text { gap.glass }=(\text { gap.rs*dailyGlass* } * \text { glass. } \\
\text { collection }) * 0.85 /(\text { glass.capacity }) .
\end{gathered}
$$

Set gap.rs $=165$, dailyGlass $=0.005 \mathrm{~m}^{3}$, glass.collection $=7$, and glass.capacity $=1.8 \mathrm{~m}^{3}$, it follows that gap.glass $=2.73$ that is rounded up to 3 . The value 0.85 introduces a margin of caution in estimating the number of GBs. Obviously, this threshold can be changed as desired or eliminated altogether.

The final step of the sizing algorithm consists of updating the fields glass, plastic, paper, organic, unsorted of gap.

\section{Implementation}

The implementation of algorithms LocatingOfGAPs and SizingOfGAPs was achieved in two steps. The first step was about the design of a SDB and its subsequent implementation in PostgreSQL/PostGIS, followed by loading in it the spatial and descriptive data necessary to solve the SWAP. Then, we coded the two algorithms in the language PL/pgSQL (http://www.post gresql.org/docs/9.1/static/plpgsql.html) as user defined functions (UDFs).

The SDB is composed of the following five tables (the primary keys are underlined):

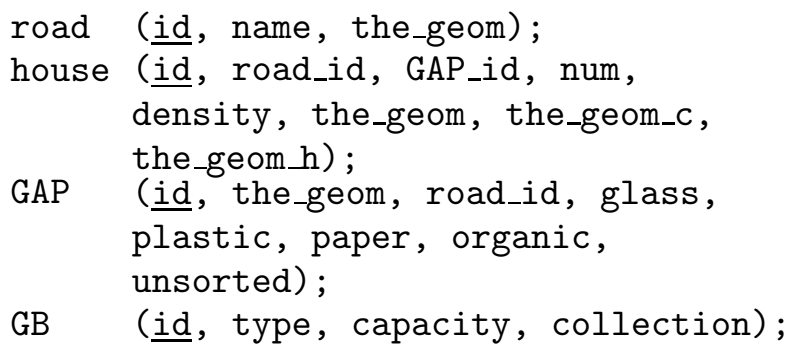

road, house, GAP, and GB store, in sequence, the elements in the sets $\mathcal{R}, \mathcal{H}, \mathcal{G} \mathcal{A P}$, and $\mathcal{G B}$.

The above relational schema comes from the conceptual schema of Figure 3, where for each entity the identifying attribute and the (min, max) participation constraints in the relationships are shown.

The implementation of algorithms LocatingOfGAPs and SizingOfGAPs as UDFs has been greatly facilitated by the use of the following PostGIS functions: ST_Area(), ST_Centroid(), ST_Distance(), ST_Intersection(), ST_Intersects(), ST_Length(), ST_Line_Interpolate Point(), ST_LineMerge (), ST_Line_Locate_Point (), ST_Line_Substring (), AddGeometryCo$\operatorname{lumn}()$.

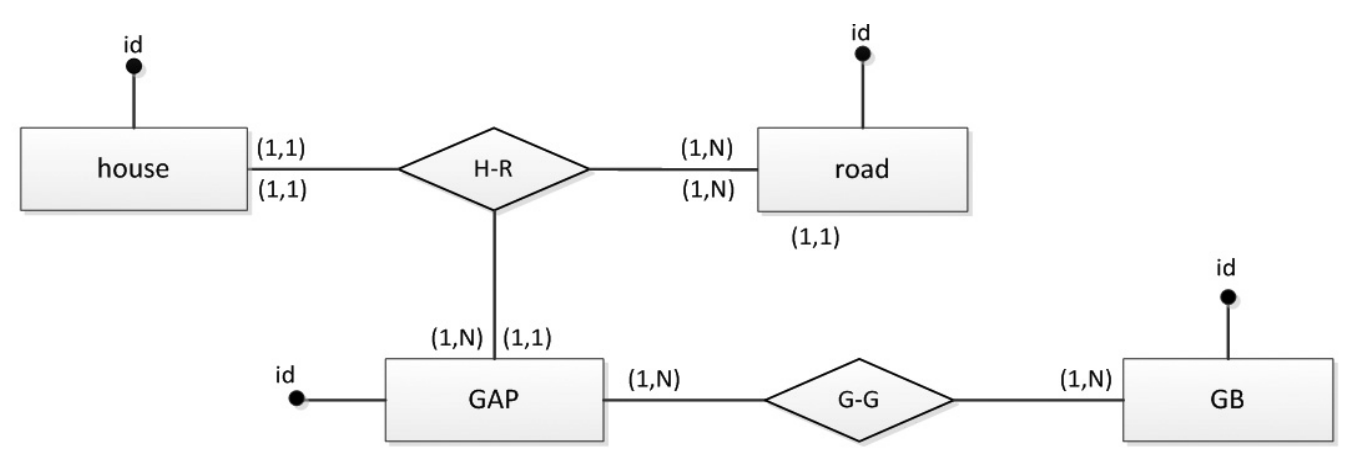

Figure 3. The conceptual schema of the SDB. 
The computation of the set $\mathrm{H}^{*}$ (Line 8, algorithm LocatingOfGAPs) with regard to a given GAP, let say gap, requires the visit of all the routes that lead to dwellings not far away from gap more than Distance moving along the public roads. This action is carried out by visiting in depth the graph having as nodes the end points of the roads in $\mathcal{R}$, the crossings between the roads in $\mathcal{R}$, the houses in $\mathrm{H}$, and the GAPs in $\mathcal{G} \mathcal{A} \mathcal{P}$ and, as arcs, segments of the roads in $\mathcal{R}$ delimited by pairs of nodes. The distances between pairs of points situated along the roads are computed as the shortest path between them.

The software architecture of the implementation (Figure 4) offers two major benefits: first of all, it relies on the SDBMS technology which

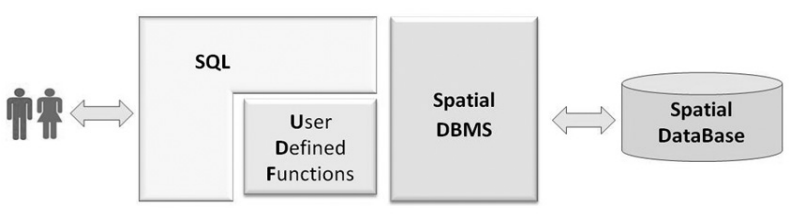

Figure 4. The software architecture of the implementation.

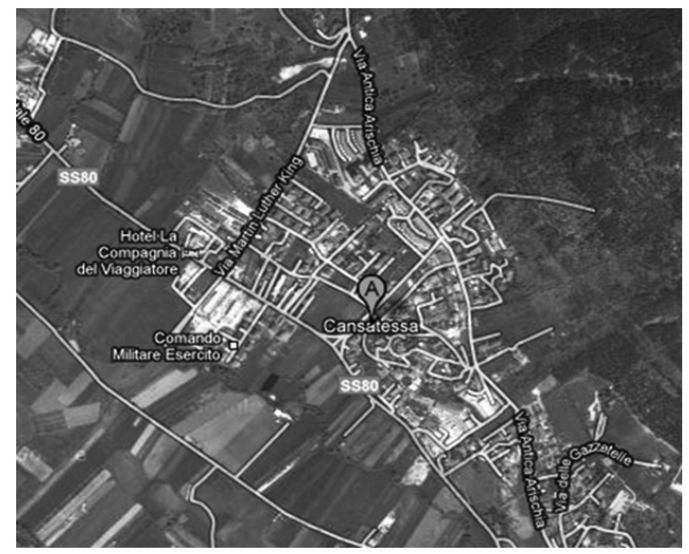

allows to take advantage of the expressiveness of the SQL language for querying the SDB (expressiveness that can be further improved by invoking either some of the implemented UDFs or the built-in functions); second, it makes exclusive use of open source software, a choice today in a sense mandatory for the municipal administrations chronically short of cash flow.

\section{Study Area and Input Datasets}

\section{The Cansatessa district}

As study area, about $7 \mathrm{~km}^{2}$, we refer to the political district of Cansatessa, part of the town of L'Aquila (the capital of the Abruzzo region; central Italy). In the district, 1464 inhabitants, are distributed in 226 buildings (Figure 5, left side), while there are 17 public roads.

L'Aquila municipality is responsible for the management of the SW life cycle in all the districts, including Cansatessa. Figure 6 shows the five categories of large-sized GBs currently adopted, while their capacity is given in Table 2.

Figure 5. A Google view of the district of Cansatessa (42 $23^{\prime} 0$ " N, $13^{\circ} 20^{\prime} 35^{\prime \prime}$ E), L'Aquila (Italy) (left side).

The public roads and the houses of Cansatessa extracted from a shape file of the Abruzzo region (right side) and displayed by using QGIS.
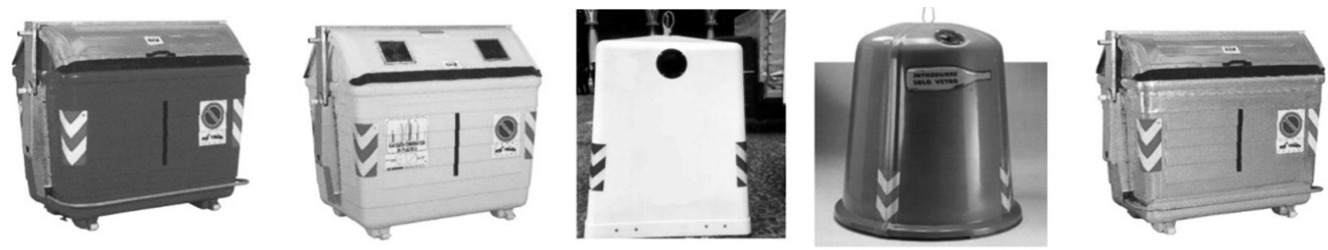

Figure 6. The categories of large-sized GBs used in all the districts of L'Aquila. From left to right they store: organic waste (i.e., biodegradable waste coming from the kitchen scraps), plastic, paper/cardboard, glass, and unsorted waste. 
According to the last available regional report (OBRA, 2011), this method of accumulation in the municipality of L'Aquila covers $83.57 \%$ of the total waste generated by the residents.

\begin{tabular}{|c|c|c|}
\hline $\begin{array}{c}\text { Types of } \\
\text { household SW }\end{array}$ & $\begin{array}{c}\text { Frequency of } \\
\text { collection }\end{array}$ & $\begin{array}{c}\text { Capacity of } \\
\text { the GBs }\left(\mathbf{m}^{3}\right)\end{array}$ \\
\hline \hline Organic & Each 3 days & 2.4 \\
Plastic & Each 3 days & 2.4 \\
Paper/cardboard & Each 5 days & 3.3 \\
Glass & Each 7 days & 1.8 \\
Unsorted & Daily & 2.4 \\
\hline
\end{tabular}

Table 2. The capacity of the different types of GBs adopted in the municipality of L'Aquila and the periodicity of collection by means of municipal garbage trucks.

Table 3 summarizes the current situation in the district of Cansatessa in terms of GAPs and GBs.

\begin{tabular}{|c|c|c|c|c|c|c|}
\hline $\begin{array}{c}\text { Total } \\
\text { number } \\
\text { of GAPs }\end{array}$ & \multicolumn{5}{|c|}{$\begin{array}{l}\text { Total number of GBs of } \\
\text { the five different types used }\end{array}$} & $\begin{array}{c}\text { Total } \\
\text { number } \\
\text { of GBs }\end{array}$ \\
\hline \multirow{2}{*}{6} & Glass & Paper & Plastic & Organic & Unsorted & \multirow{2}{*}{30} \\
\hline & 5 & 5 & 5 & 6 & 9 & \\
\hline
\end{tabular}

Table 3. GAPs and GBs in Cansatessa.

\section{The datasets}

The datasets concern both spatial and descriptive data.

\section{The spatial data}

The spatial data concerning public roads and houses of Cansatessa were extracted (in the ESRI shape format) from the Regional Numerical Map at the 1-5000 scale provided by the Abruzzo Region (http://www.regione.abruz zo.it/xcartografia/). Figure 5 (right side) shows the content of this shape using QGIS. These spatial data are sufficient to feed the algorithm LocatingOfGAPs.

\section{The descriptive data}

The situation is much more complex with regard to the descriptive data necessary to feed the algorithm SizingOfGAPs. The data we are talking about concern the number of people living inside the dwellings and their per capita daily production of SW of different types. Having reliable data at this level of detail is not trivial because, as stated in recent field studies (e.g., Lebersorger \& Beigl, 2011), these values are dependent on many variables, including time of the year, weather, household income, size of their homes, type of heating system in the apartments, etc.

Over time volatility of data is another critical issue against the acquisition of reliable data to feed the algorithm SizingOfGAPs. In fact, what we are witnessing is that, partly because of the legislative pressures that exist in all European countries, the quotas of separate collection of municipal SW increase from year to year. By contrast, the data available date back to several years ago. For example, the latest study within the Abruzzo region (OBRA, 2011) reports the data from 2009.

Last practical difficulty, but certainly not the least, comes from the fact that there is no unique transformation ratio between the weight of SW (expressed in $\mathrm{kg}$ ) and its volume, while it is precisely from these data that we need to solve the SWAP properly, given that the capacity of the GBs is expressed in $\mathrm{m}^{3}$. Nor are there any studies on the subject (as far as we know) from which to draw them. The relevance of this issue has been stressed recently by Hoornweg \& Bhada-Tata (2012), where we read: "Although waste composition is usually provided by weight, waste volumes tend to be more important, especially with regard to accumulation".

All the above mentioned issues have a direct impact on the outcome of the sizing stage. Therefore, it is correct to say that the goodness of the estimates provided by the method proposed in Section 3 (as well as any other similar method) largely depends on the accuracy of the input data.

In the present pilot study, given the impossibility of making use of updated data on a local basis, we adopted "synthetic" data (Table 4). The 2nd column sets the number of residents served by a specific GB before it becomes full at $85 \%$, according to the weekly periodicity of collection of the SW by the municipal workers. So, for instance, from Table 4 we learn that a GB of Glass type can serve at the most 120 people within seven days.

The number of people living inside the dwellings was acquired through a door-to-door survey. 


\begin{tabular}{|l|c|}
\hline $\begin{array}{c}\text { Category of } \\
\text { household SW }\end{array}$ & $\begin{array}{c}\text { Number of residents } \\
\text { served by one GB }\end{array}$ \\
\hline \hline Organic & 80 \\
Plastic & 130 \\
Paper/cardboard & 100 \\
Glass & 120 \\
Unsorted & 210 \\
\hline
\end{tabular}

Table 4. The descriptive data used to run the algorithm SizingOfGAPs.

\section{Results and Discussion}

\section{Locating of the GAPs}

First campaign of experiments

As first set of experiments, the Locating OfGAPs algorithm was run varying the value of the Distance parameter as follows: 50, 100, 150, 200, 250, 300, 500 (meters). The findings in (Parrot et al., 2009) advise against going further. The seven experiments were repeated three times changing the order in which the roads in the set $\mathcal{R}$ were visited. Table 5 collects the results of the campaign of experiments.

\begin{tabular}{|c|c|c|c|}
\cline { 2 - 4 } \multicolumn{1}{c|}{} & \multicolumn{3}{c|}{ Number of GAPs } \\
\hline $\begin{array}{c}\text { Distance } \\
(\mathrm{m})\end{array}$ & $\begin{array}{c}\text { Order no.1 } \\
\text { of visit } \\
\text { of the roads }\end{array}$ & $\begin{array}{c}\text { Order no.2 } \\
\text { of visit } \\
\text { of the roads }\end{array}$ & $\begin{array}{c}\text { Order no.3 } \\
\text { of visit } \\
\text { of the roads }\end{array}$ \\
\hline \hline 50 & 41 & 41 & 41 \\
\hline 100 & 27 & 27 & 27 \\
\hline 150 & 22 & 20 & 21 \\
\hline 200 & 16 & 17 & 18 \\
\hline 250 & 13 & 14 & 13 \\
\hline 300 & 9 & 10 & 9 \\
\hline 500 & 5 & 6 & 5 \\
\hline
\end{tabular}

Table 5. The results of the first campaign of experiments.

As it was predictable, the number of GAPs decreases as the value of Distance increases. But Table 5 also shows that the number of GAPs is affected by the order in which the first algorithm visits the public roads. This dependence is deepened below.
Second campaign of experiments

The second campaign of experiments consisted of running LocatingOfGPAs for the same seven values of the parameter Distance as in the first campaign of experiments, but in two extreme situations: for descending (ascending) values of the length of the roads (Table 6). In other words, in the first seven runs, the algorithm locates the GAPs first on the public road $1493 \mathrm{~m}$ long, then on that $1046 \mathrm{~m}$ long, and so on. While in the next seven runs it locates the GAPs first on the public road $80 \mathrm{~m}$ long, then on that $85 \mathrm{~m}$ long, and so on.

\begin{tabular}{|c|c|c|}
\hline$\#$ & Road id & Length (m) \\
\hline 1 & 15 & 1493 \\
\hline 2 & 17 & 1046 \\
\hline 3 & 4 & 632 \\
\hline 4 & 5 & 400 \\
\hline 5 & 9 & 359 \\
\hline 6 & 14 & 270 \\
\hline 7 & 1 & 242 \\
\hline 8 & 3 & 217 \\
\hline 9 & 11 & 206 \\
\hline 10 & 6 & 188 \\
\hline 11 & 2 & 187 \\
\hline 12 & 7 & 163 \\
\hline 13 & 13 & 146 \\
\hline 14 & 10 & 114 \\
\hline 15 & 8 & 111 \\
\hline 16 & 16 & 85 \\
\hline 17 & 12 & 80 \\
\hline
\end{tabular}

Table 6. The 17 public roads in Cansatessa, listed for descending value of their length.

Table 6 was built by querying the SDB by means of the following spatial query:

$$
\begin{array}{ll}
\text { SELECT id, round(ST_Length(ST_LineMerge } \\
\\
\text { (the_geom)): :numeric) AS Length } \\
\text { FROM road }
\end{array}
$$

ORDER BY ST_Length (ST_LineMerge(the_geom)) DESC

Table 7 collects the results of the second campaign of experiments. 


\begin{tabular}{|c|c|c|}
\hline $\begin{array}{c}\text { Distance } \\
(\mathbf{m})\end{array}$ & $\begin{array}{c}\text { Roads visited in } \\
\text { descending order }\end{array}$ & $\begin{array}{c}\text { Roads visited in } \\
\text { ascending order }\end{array}$ \\
\hline \hline 50 & 41 & 41 \\
\hline 100 & 25 & 27 \\
\hline 150 & 18 & 23 \\
\hline 200 & 12 & 19 \\
\hline 250 & 8 & 15 \\
\hline 300 & 7 & 10 \\
\hline 500 & 4 & 6 \\
\hline
\end{tabular}

Table 7. The results of the second campaign of experiments.

Figure 7 shows the geographic position of the GAPs for Distance $=250 \mathrm{~m}$ and Distance $=300 \mathrm{~m}$ when the roads are visited in descending order of length.

Table 7 and Figure 7 make evident that the best strategy of crossing the public roads (by algorithm LocatingOfGAPs) is for descending values of their length. In fact, for any value of Distance, such an option gives rise to the lowest number of GAPs, moreover, the algorithm locates the GAPs first on the streets of greater extension that, likely, are also those that offer the best road conditions. This latter aspect is fundamental for the operations of garbage collection by means of the municipal trucks.

A confirmation of the latter statement is found in Figure 8 , from which we can see that in case the roads are visited in increasing order of length, and set Distance $=250 \mathrm{~m}$, the LocatingOfGAPs algorithm locates several GAPs in roads very short (i.e., 16, 7, 8, 13, 2), in contrast to what is observed in Figure 7 for the corresponding case.

Table 8 , built by querying the SDB with the following SQL query:

SELECT g.id AS GAP_id, g.road_id AS Road _id, round(ST_Length(ST_LineMerge (r.the_geom)) : :numeric) AS Road Length

FROM GAP AS g, road AS $r$

WHERE g.road_id = r.id;

shows that the situation Distance $=300 \mathrm{~m}$ is the most favorable from this point of view. In fact, it happens that five out of the seven GAPs (Table 7) are located on the three longer public

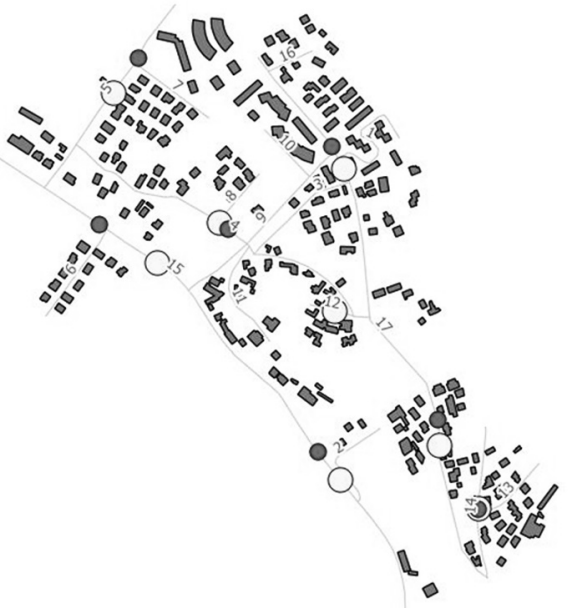

Figure 7. The (8) big and (7) small circles, respectively, denote the GAPs for Distance $=250 \mathrm{~m}$ and Distance $=300 \mathrm{~m}$. The numbers are the identifiers of the roads. The map is made with QGIS.

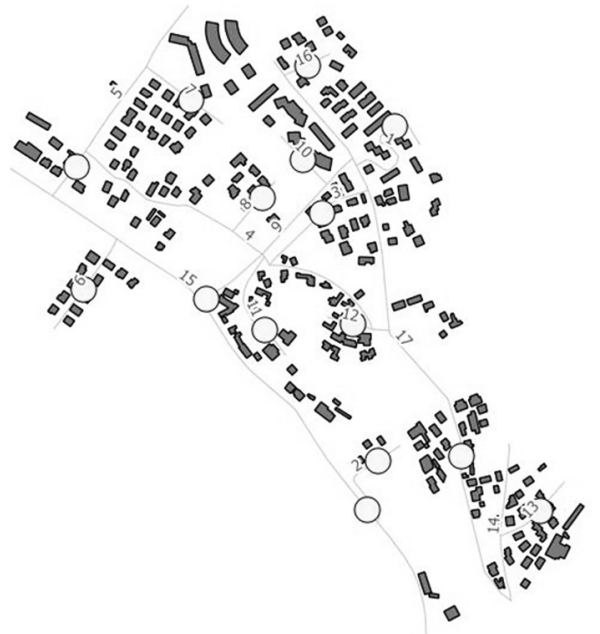

Figure 8. The geographical position of the 15 GAPs for Distance $=250 \mathrm{~m}$, when the roads are visited in ascending order of length.

\begin{tabular}{|c|c|c|}
\hline GAP_id & Road_id & Road_Length \\
\hline \hline 1 & 15 & 1493 \\
\hline 2 & 15 & 1493 \\
\hline 3 & 17 & 1046 \\
\hline 4 & 17 & 1046 \\
\hline 5 & 4 & 632 \\
\hline 6 & 5 & 400 \\
\hline 7 & 14 & 270 \\
\hline
\end{tabular}

Table 8. Road's id and length where the GAPs are located when Distance $=300 \mathrm{~m}$ and the roads are visited in descending order of length. 
roads in the Cansatessa district. The positioning of the GAPs obtained when Distance $=250 \mathrm{~m}$ is less satisfactory (Figure 7).

\section{Sizing of the GAPs}

Third campaign of experiments

It was about the execution of the SizingOfGAPs algorithm for the same seven values of the Distance parameter. Then, we extracted the results (Table 9), collected in the SDB, using the following SQL query:

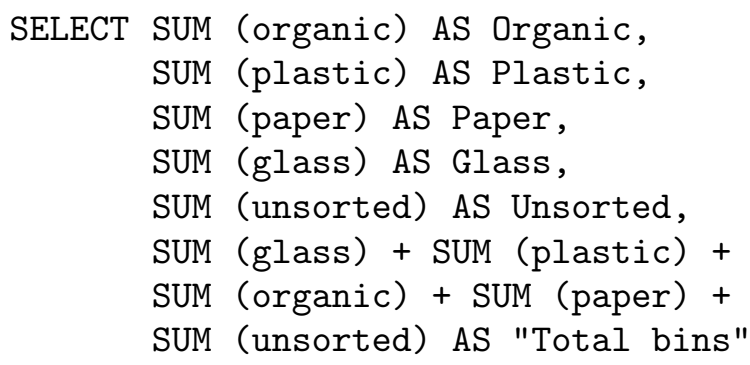

FROM GAP

The 9th column shows that the average number of GBs per GAP increases (from 5.2 GBs to 18.8 ) as the number of GAPs decreases. The values in the column "Total bins" show, however, that the total number of GBs decreases as the GAPs decrease. This result, apparently surprising, can be interpreted by remembering that every GAP consists of at least $5 \mathrm{GBs}$, one for each category of SW. Since Distance $=50 \mathrm{~m}$ gives rise to 41 GAPs, it follows that the minimum number of GBs is (equal to) 205 (very close to the value 213); while Distance $=500 \mathrm{~m}$ gives rise to 4 GAPs, which corresponds to a minimum number of 20 GBs (significantly below 75).
The 10th column shows the average value of the area occupied by a GAP, assuming that the area of a single GB is equal to $1.5 \mathrm{~m}^{2}$ (this value is in line with the size of the GBs available from the network. An example: Pack Services Srl, http://www. packservices.it).

Lastly, the column "Cost" gives an estimate of the initial investment to be supported. For simplicity, it is assumed that the GBs of different types have the same cost $(115 €$, source: http://www.alibaba.com). It does not escape the huge difference that exists between the extreme cases (Distance $=50 \mathrm{~m}$ and Distance $=500 \mathrm{~m}$ ) due to the 3 to 1 ratio on the total number of GBs. This gap, kept down for the small district of Cansatessa (226 houses and 1,464 residents), becomes relevant if the urban dimension to be served is larger. For instance, in the case of a district hundred times bigger, the initial investment for the two extreme cases is of the order, respectively, of $2.5 \mathrm{M} €$ and $8.6 \mathrm{~K} €$.

The general finding that can be extracted from the experiments (Table 9) is that the value of the Distance parameter should fall between $250 \mathrm{~m}$ and $300 \mathrm{~m}$. There are two major reasons supporting this choice:

- the resulting number of GAPs and GBs is limited. This implies that the overall waste collection time by the municipal workers is significantly reduced;

- the total number of GBs to be bought is significantly lower than that in the extreme case (Distance $=50 \mathrm{~m})$, which implies a considerable economic saving.

From Table 3 and Table 9, we see that the total number of GAPs in Cansatessa is compara-

\begin{tabular}{|c|c|c|c|c|c|c|c|c|c|c|}
\hline Distance (m) & GAPs & Organic & Plastic & Paper & Glass & Unsorted & Total bins & GBs/GAPs & $\begin{array}{c}\text { Average area } \\
\text { of the GAP }\left(\mathbf{m}^{2}\right)\end{array}$ & Cost ( $€)$ \\
\hline \hline 50 & 41 & 49 & 41 & 41 & 41 & 41 & 213 & 5.2 & 7.8 & 24,495 \\
\hline 100 & 25 & 35 & 26 & 25 & 25 & 26 & 137 & 5.5 & 8.2 & 15,755 \\
\hline 150 & 18 & 33 & 20 & 19 & 19 & 20 & 111 & 6.2 & 9.2 & 12,765 \\
\hline 200 & 12 & 31 & 18 & 15 & 15 & 18 & 97 & 8 & 12 & 11,155 \\
\hline 250 & 8 & 28 & 17 & 11 & 13 & 17 & 86 & 10.8 & 16.1 & 9,890 \\
\hline 300 & 7 & 29 & 15 & 12 & 12 & 15 & 83 & 11.9 & 17.8 & 9,545 \\
\hline 500 & 4 & 27 & 14 & 10 & 10 & 14 & 75 & 18.8 & 28.1 & 8,625 \\
\hline
\end{tabular}

Table 9. The results of the third campaign of experiments. 
ble with the outcome produced by our method when Distance $=300 \mathrm{~m}$ (6 vs. 7 ), but the total number of GBs is definitely insufficient (30 vs. 83). This big mismatch makes evident that the method of allocation adopted nowadays by the municipalities is unsatisfactory. The inevitable consequence is that very often the GBs are full, so it is common to run into scenes like that in Figure 9.

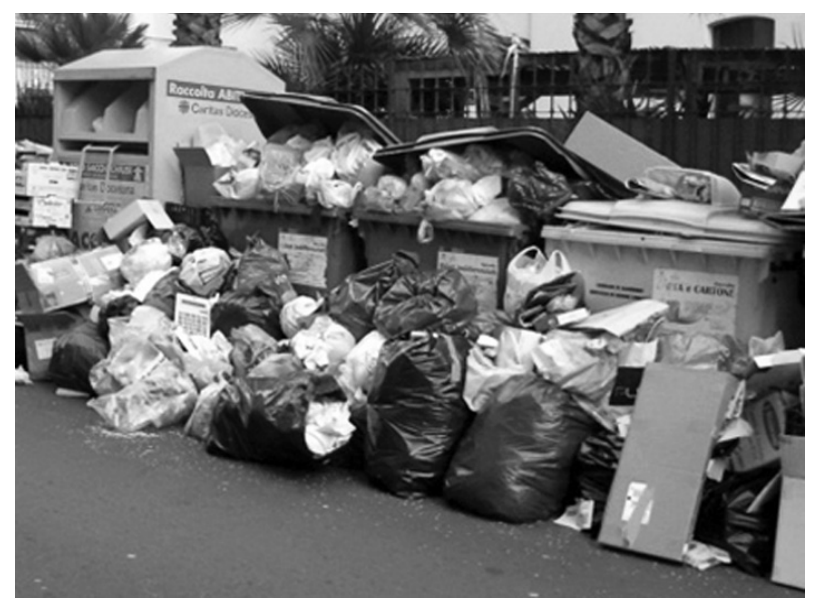

Figure 9. Litter exceeding the storage capacity of the GBs at a GAP.

\section{A Nice Feature of the Algorithm LocatingOfGAPs: the Flexibility}

At this point we have all the elements to focus on an interesting behavioral trait of the first algorithm. Let gap be a GAP whose position on the territory has been identified by LocatingOfGAPs moving along the public road $r$. When the algorithm proceeds to explore the roads that are located in the neighborhood of gap (let $r^{*}$ be one of them), two complementary situations can arise: $r^{*}$ ends before a movement along $r^{*}$, starting from gap, equal to Distance has been accomplished (for brevity we will use the notation: length $\left(\right.$ gap_r $\left.r^{*}\right)<=$ Distance $)$, conversely length $\left(\right.$ gap_r* $\left.{ }^{*}\right)>$ Distance. In the first case, $L o$ cating OfGAPs assigns the houses in the residual stretch of $r^{*}$ (if any) to gap; while it manages the second case with a certain degree of flexibility, as explained below by referring to Figure 10 .

In Figure 10, the inner area denotes the portion of the urban territory which is far from gap at most Distance (moving along the public roads of the district), while the crown adds to the internal area a stretch of the public roads equal to $\delta$, an arbitrary value much lesser than Distance. Figure 10 shows, moreover, the three different situations that may arise during the visit of $r^{*}$ (below renamed $r_{1} *, r_{2}^{*}$, and $r_{3} *$ to avoid confusing the reader). In the figure, the points $a, b$, and $c$ are distant exactly Distance from gap by moving along $r_{1}{ }^{*}, r_{2} *$ and $r_{3} *$.

The following three cases are possible when length $\left(\right.$ gap $\left.\_*\right)>$ Distance:

1. length $\left(r_{1} *+\delta\right)<=$ Distance, i.e., starting from gap, $r_{1} *$ ends before a movement equal to Distance $+\delta$ has been accomplished along such a road. All the houses on $\mathrm{r}_{1} *$, between point $a$ and the end of $r_{1} *$ (two in Figure 10), are assigned to gap;

2. length $\left(r_{2}^{*}+\delta\right)>$ Distance, but beyond the gray crown there are no other houses to be served, while there are some inside the crown (one in Figure 10). LocatingOfGAPs assigns those dwellings to gap;

3. length $\left(r_{3} *+\delta\right)>$ Distance, but beyond the crown there are other houses. In this case LocatingOfGAPs will ignore any dwellings inside the crown (Figure 10 shows one of them) that will be assigned to a GAP to be positioned when the algorithm visits $r_{3}{ }^{*}$.

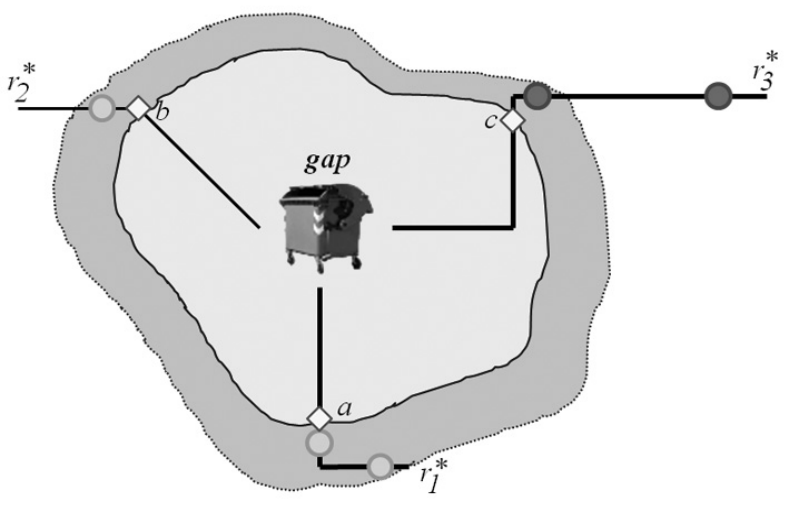

Figure 10. The light gray centroids denote dwellings assigned to gap, while the dark gray ones denote dwellings not served by gap. The three diamonds denote the points $a, b$, and $c$.

The first half of Table 10 repeats results from Table 9 (obtained by setting $\delta=25 \% *$ Distance), while the second half shows the values that we obtained by eliminating from LocatingOfGAPs the flexibility pointed out previously; for such a reason called "LocatingOfGAPs blind" in the table as well as in the remainder of the paper. 
Table 10, besides confirming what was reasonable to expect (i.e., a systematic increase, for the same value of Distance, of the total number of GAPs and GBs returned by the algorithm LocatingOfGAPs blind with respect to LocatingOfGAPs), moreover quantifies that the amount of saving we got in the pilot study is modest. Notice that it is not possible to predict the amount of saving for given values of Distance and $\delta$ since it depends on the geography of the district. Obviously, it is up to the recipients of our method to carry out a campaign of experiments (for several values of Distance and $\delta$ ) in order to identify the best trade-off for the district to be served.

There is a similarity between the "tolerance parameter $-\delta$ " in (Ghiani et al., 2012) and our $\delta$. They set $\delta=10 \% *$ Distance in the experiments.

Table 11 shows fluctuations in the number of GAPs and GBs (for the Cansatessa district) when $\delta$ varies from $10 \%$ to $50 \%$ of Distance.
To not excessively distort the behavior of the algorithm LocatingOfGAPs, it is important that the value of $\delta$ is kept much lesser than Distance. For this reason, we suggest do not enter the gray area of Table 11. Doing so, the maximum value of $\delta$ is equal to $20 \mathrm{~m}, 30 \mathrm{~m}, 30 \mathrm{~m}, 40 \mathrm{~m}, 50 \mathrm{~m}$, $30 \mathrm{~m}$ and $50 \mathrm{~m}$ when Distance varies from $50 \mathrm{~m}$ to $500 \mathrm{~m}$, respectively.

The impact of the flexibility of the algorithm LocatingOfGAPs in exploring the roads in the neighborhood of a GAP is especially important to pursue management of the final stretch of the public roads (a situation which can be traced back to the case of $r_{1}^{*}$ and $r_{2} *$ in Figure 10) that may be satisfactory from the point of view of the managers of SW collection service. In fact, the shorter the final stretch of the roads, relative to the value of Distance, the less they are inclined towards allocating further GAPs.

\begin{tabular}{|c|c|c|c|c|c|c|c|c|}
\cline { 2 - 9 } \multicolumn{1}{c|}{} & \multicolumn{3}{c|}{ LocatingOfGAPs $(\delta=25 \% *$ Distance $)$} & \multicolumn{4}{c|}{ LocatingOfGAPs blind } \\
\hline Distance $(\mathrm{m})$ & GAPs & GBs & GBs/GAP & $\begin{array}{c}\text { Average area of } \\
\text { the GAP }\left(\mathrm{m}^{2}\right)\end{array}$ & GAPs & GBs & GBs/GAP & $\begin{array}{c}\text { Average area of } \\
\text { the GAP }\left(\mathrm{m}^{2}\right)\end{array}$ \\
\hline \hline 50 & 41 & 213 & 5.2 & 9 & 43 & 223 & 5.2 & 7.8 \\
\hline 100 & 25 & 137 & 5.5 & 9 & 28 & 151 & 5.4 & 8.1 \\
\hline 150 & 18 & 111 & 6.2 & 10.5 & 22 & 130 & 5.9 & 8.8 \\
\hline 200 & 12 & 97 & 8 & 12 & 15 & 111 & 7.4 & 11.1 \\
\hline 250 & 8 & 86 & 10.8 & 16.5 & 12 & 104 & 8.7 & 13 \\
\hline 300 & 7 & 83 & 11.9 & 18 & 8 & 87 & 10.9 & 16.3 \\
\hline 500 & 4 & 75 & 18.8 & 28.5 & 6 & 82 & 13.7 & 20.5 \\
\hline
\end{tabular}

Table 10. A comparison of the results computed by LocatingOfGAPS and LocatingOfGAPs blind for the district of Cansatessa.

\begin{tabular}{|c|c|c|c|c|c|c|c|c|c|c|}
\cline { 2 - 13 } \multicolumn{1}{c|}{} & \multicolumn{2}{c|}{$\delta=10 \%$} & \multicolumn{2}{c|}{$\delta=20 \%$} & \multicolumn{2}{c|}{$\delta=30 \%$} & \multicolumn{2}{c|}{$\delta=40 \%$} & \multicolumn{2}{c|}{$\delta=50 \%$} \\
\hline Distance $(\mathrm{m})$ & GAPs & GBs & GAPs & GBs & GAPs & GBs & GAPs & GBs & GAPs & GBs \\
\hline \hline 50 & 43 & 223 & 43 & 223 & 41 & 213 & 41 & 213 & 40 & 208 \\
\hline 100 & 27 & 147 & 25 & 137 & 24 & 132 & 24 & 132 & 22 & 128 \\
\hline 150 & 20 & 121 & 18 & 111 & 18 & 111 & 17 & 107 & 15 & 104 \\
\hline 200 & 14 & 106 & 13 & 101 & 12 & 99 & 11 & 94 & 11 & 93 \\
\hline 250 & 9 & 91 & 9 & 91 & 8 & 86 & 8 & 86 & 7 & 83 \\
\hline 300 & 7 & 83 & 7 & 83 & 7 & 83 & 7 & 82 & 7 & 83 \\
\hline 500 & 5 & 80 & 4 & 75 & 4 & 75 & 4 & 75 & 4 & 74 \\
\hline
\end{tabular}

Table 11. Fluctuations in the number of GAPs and GBs. 


\section{Concluding Remarks}

Table 9 tells us that as Distance increases the number of GAPs decreases (as well as the number of the GBs), so it is obvious that the number of GAPs for Distance $+\delta$ (for any $\delta>0$ ) must be less than that got for Distance. The values in Table 10 confirm this statement. However, it is important to emphasize that the flexibility of the first algorithm cannot be replaced by $\mathrm{LO}$ catingOfGAPs blind through the increase of the parameter Distance to the value Distance $+\delta$. Indeed, there is no increase of $\delta$ able to distinguish the second case in Figure 10 from the third one.

Table 12 compares the results of LocatingOfGAPs with those of LocatingOfGAPs blind, the latter run by setting Distance $=$ Distance of Locating Of GAPs $+\delta$ (for example, the values returned by LocatingOfGAPs per Distance $=$ $100 \mathrm{~m}$, are compared with those returned by $L o$ catingOfGAPs blind run by setting Distance $=$ $125 \mathrm{~m})$.

\begin{tabular}{|c|c|c|c|c|c|}
\hline \multicolumn{2}{|c|}{ LocatingOfGAPs $(\boldsymbol{\delta}=25 \%)$} & \multicolumn{3}{|c|}{ LocatingOfGAPs blind } \\
\hline Distance $(\mathrm{m})$ & GAPs & GBs & Distance $(\mathrm{m})$ & GAPs & GBs \\
\hline \hline 50 & 41 & 213 & 62.5 & 37 & 194 \\
\hline 100 & 25 & 137 & 125 & 24 & 135 \\
\hline 150 & 18 & 111 & 187.5 & 15 & 109 \\
\hline 200 & 12 & 97 & 250 & 12 & 104 \\
\hline 250 & 8 & 86 & 312.5 & 7 & 81 \\
\hline 300 & 7 & 83 & 375 & 7 & 81 \\
\hline 500 & 4 & 75 & 625 & 4 & 73 \\
\hline
\end{tabular}

Table 12. Comparison between LocatingOfGAPs and LocatingOfGAPs blind.

As we can see, the total number of GAPs calculated by LocatingOfGAPs blind is less than or equal to the corresponding value calculated by LocatingOfGAPs. We can also note that the deviations decrease as Distance increases, to disappear when Distance $>=300 \mathrm{~m}$. About the GBs, we can see that their total number calculated by LocatingOfGAPs blind is always less than the corresponding value calculated by LocatingOfGAPs. Also in this case the deviations, large for low values of Distance, rapidly decline as Distance increases, and almost disappear when Distance $>=300 \mathrm{~m}$.
In summary, it can be said that the reason for the deviations in Table 12 is that while LocatingOfGAPs tries an action of adjustment of type "local" (according to the schema of Figure 10), that does not always produce savings in the number of GAPs (and, hence, of GBs), LocatingOfGAPs blind, vice versa, proceeds to the positioning of the GAPs by setting a constraint about the maximum distance GAP-house less stringent and that produces a saving that is more evident the more we operate at low values of Distance.

\section{Analysis on Demand}

As already remarked (Section 4), the strength of the adopted software architecture resides in the technology of the SDBMSs which offers the expressiveness of the SQL language in querying the SDB. The seven queries (consistent with the PostgreSQL/PostGIS syntax) that follow give a concrete proof of the previous statement. Evidently, other requirements of analysis that might occur to those who have the responsibility for the management of the SW can be satisfied in the same way.

Q1 Retrieve the total number of the citizens served by each allocated GAP when Distance $=300 \mathrm{~m}$. Order the returned tuples in ascending order of the GAP's identifier.

$\begin{array}{ll}\text { SELECT } & \text { gap_id AS "GAP Id", } \\ & \begin{array}{l}\text { SUM(density) AS } \\ \text { "citizens served" }\end{array} \\ \text { FROM } & \text { house } \\ \text { GROUP BY gap_id } \\ \text { ORDER BY gap_id ASC }\end{array}$

The output is shown in Table 13.

\begin{tabular}{|c|c|}
\hline GAP Id & citizens served \\
\hline \hline 1 & 88 \\
\hline 2 & 205 \\
\hline 3 & 232 \\
\hline 4 & 446 \\
\hline 5 & 144 \\
\hline 6 & 212 \\
\hline 7 & 137 \\
\hline
\end{tabular}

Table 13. The result of $\mathbf{Q 1 .}$ 
Q2 Retrieve the total number of the houses served by each allocated GAP when Distance $=300 \mathrm{~m}$. Order the returned tuples in ascending order of the GAP's identifier.

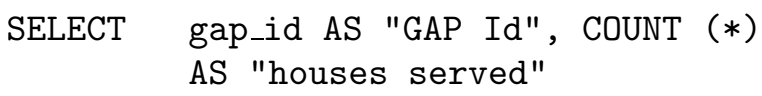

FROM house

GROUP BY gap_id

ORDER BY gap_id ASC

The output is shown in Table 14.

\begin{tabular}{|c|c|}
\hline GAP Id & houses served \\
\hline \hline 1 & 15 \\
\hline 2 & 37 \\
\hline 3 & 41 \\
\hline 4 & 62 \\
\hline 5 & 24 \\
\hline 6 & 23 \\
\hline 7 & 24 \\
\hline
\end{tabular}

Table 14. The result of $\mathbf{Q 2}$.

Q3 Retrieve the identifier of the houses served by each allocated GAP. Order the tuples in ascending order of GAP's identifier.

$\begin{array}{ll}\text { SELECT } & \begin{array}{l}\text { gap_id AS "GAP Id", id AS } \\ \text { "house Id" }\end{array} \\ \text { FROM } & \text { house } \\ \text { GROUP BY gap_id, id } \\ \text { ORDER BY gap_id ASC }\end{array}$

Output not shown because composed of too many tuples (226).

Q4 Retrieve, for each GAP, the value of the average of the distances of the houses served by it. (The SQL formulation refers to Distance $=300 \mathrm{~m}$.)

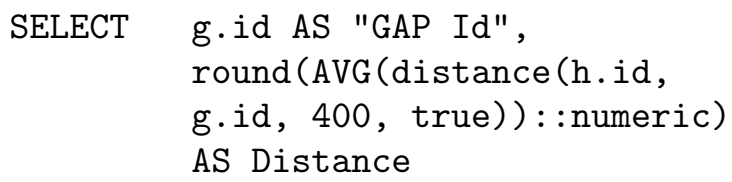

FROM gap AS $g$, house AS $h$

WHERE
St_Distance (g. the_geom, $h$. the_geom $h$ ) $<=300$ AND distance(h.id, g.id, 400, true)

$<=300$ AND $\mathrm{h} \cdot$ gap_id $=\mathrm{g} \cdot \mathrm{id}$

GROUP BY g.id

The output is shown in Table 15.

\begin{tabular}{|c|c|}
\hline GAP Id & AVG distance house - GAP \\
\hline \hline 1 & 198 \\
\hline 2 & 162 \\
\hline 3 & 85 \\
\hline 4 & 139 \\
\hline 5 & 114 \\
\hline 6 & 150 \\
\hline 7 & 75 \\
\hline
\end{tabular}

Table 15. The result of Q4.

In Q4, St_Distance () is a PostGIS spatial function, while distance () is one of our UDFs. The first function computes the Euclidean distance between two points (in our case, the position occupied by the GAP and the projection of the centroid of the house on the reference road), while the second function computes the distance between the same two points but moving along the public roads. The condition ST_Distance (...) $<=300$ speeds up the computation of $\mathbf{Q 4}$, in fact it asks to ignore all the dwellings that are located more than $300 \mathrm{~m}$ as the crow flies, because they will certainly be at a distance not less than $300 \mathrm{~m}$ when moving along the roads.

Q5 Retrieve the value of the overall average of the distances dwelling-(reference)GAP, when Distance $=300 \mathrm{~m}$.

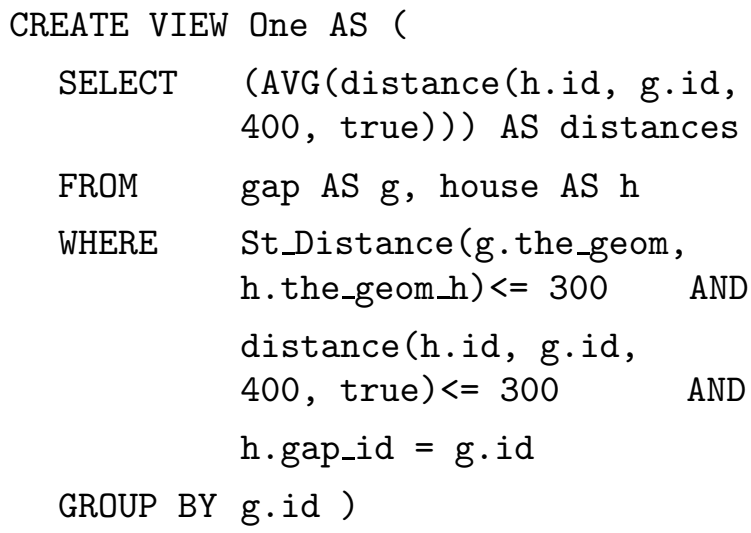

FROM one 
The output is shown in Table 16.

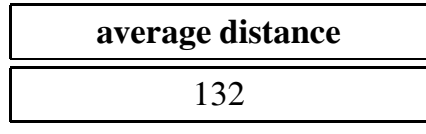

Table 16. The result of Q5.

The necessity to introduce the view one comes from the impossibility of nesting built-in functions (in the example: SUM and AVG) in the PostgreSQL version we used.

All the previous queries return information in the standard relational format. However, having implemented a SDB, it makes trivial to combine this method of displaying of the results with the construction of maps. Below, we propose two examples, but many others are possible.

Q6 Retrieve the location of the dwellings served by GAP 5 and Distance $=300 \mathrm{~m}$.

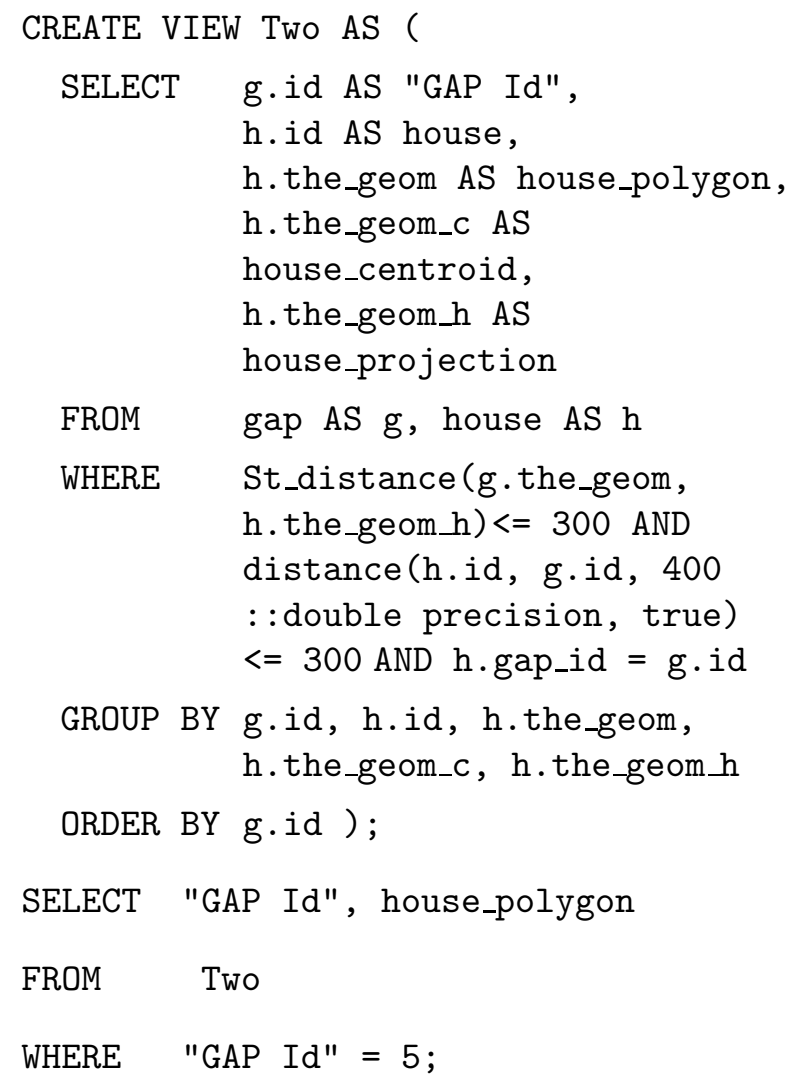

The output returned by Q6 is tabular. Figure 11 shows its visualization through QGIS.

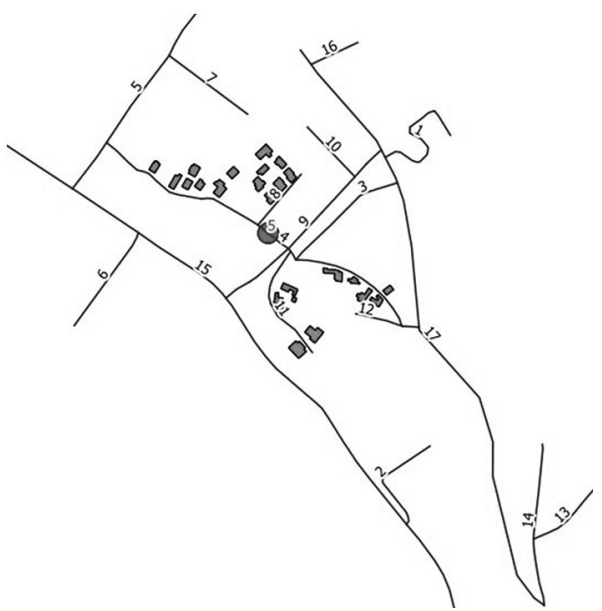

Figure 11. A GIS map built starting from the output of Q6. The figure shows the twenty-four dwellings served by GAP 5 and their reference roads (namely: 4,8 and 11 ).

Q7 Retrieve the ID and position of the GAPs located along the road "VIA LUDWIG VAN BEETHOVEN" $(\mathrm{id}=4)$ and Distance $=300 \mathrm{~m}$.

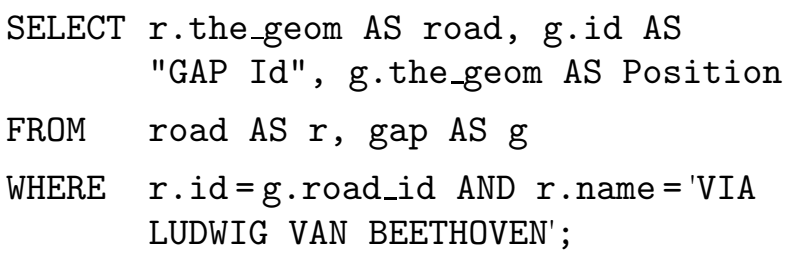

The map in Figure 12 shows that only one GAP (the small circle) is located along the entered road $(\mathrm{id}=4)$.

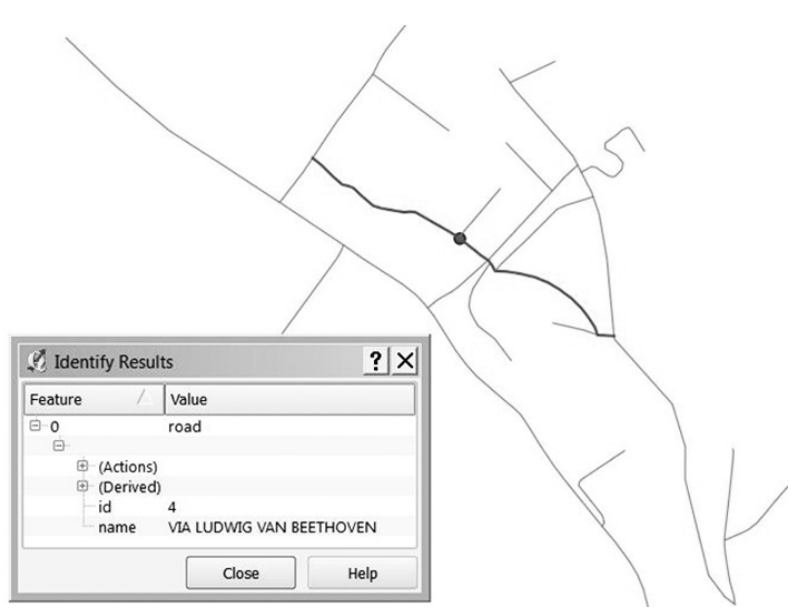

Figure 12. A QGIS map built starting from the output of Q7.

In summary, $\mathbf{Q} 2$ and $\mathbf{Q 3}$ provide a twofold "numerical view" about how various GAPs serve 
the dwellings of the Cansatessa's district. Q2 provides a global information, while $\mathbf{Q 3}$ provides details about the coupling housing-GAP of reference.

Q4 returns, for each GAP, the value of the average distance of the houses it serves, while Q5 shows the value of the overall average of the distances between each dwelling and its reference GAP. Both those values are of interest to the managers of the service because they provide them with "global" information that enrich the starting data, i.e., the value of the Distance parameter. The value returned by $\mathbf{Q 5}(132 \mathrm{~m})$ gives the chance to recall the experiments made by Ghiani et al. (2012). They restricted their attention to the values 140 and 150 meters as the maximum distance house-GAP of reference, with the following explanation: those values "are typical distances that can be easily covered in urban areas". The value $132 \mathrm{~m}$ reinforces our belief that the adoption of the constraint Distance $=300 \mathrm{~m}$ might be appropriate in the reality. The added value of the last two queries, compared to the others, is that they also return geometric information, necessary to produce geographic maps invaluable for decision makers.

\section{Conclusions and Further Work}

Complex decision problems are frequently encountered in urban planning, typically involving the consideration of a large number of conflicting objectives. The method proposed in this paper is able to produce a lot of information to support the persons responsible for the management of the municipal SW in setting, in full autonomy, and in the "real world", a satisfactory trade-off between the maximum distance dwelling-GAP of reference and the number/sizing of the GAPs.

The proposed method was implemented with open source software and then used to carry out a pilot study. The study confirmed what was in a sense obvious to expect, namely that as the distance increases, the number of GAPs decreases. Having few areas of accumulation definitely accelerates the waste collection by the municipal workers, while, on the citizens' side, this may cause some drawbacks. First of all, such a solution forces many residents to use the car to go to drop the SW into the GBs, which may not be the case if the reference GAP is closer (e.g., within $100 \mathrm{~m}$ ). It is also plausible to foresee that such a solution may have impact on the aesthetics of the area, on the smells, as well as on the commercial value of the surrounding dwellings. Another aspect not to be underestimated is the fact that it may not be trivial to find, within modern urban areas, sites adequate to accommodate large GAPs. Last, but not least, decision makers may be constrained in the choice of a solution by the budget available. Our study pointed out clearly that the initial investment to buy the GBs decreases as the value of Distance increases.

In closing, it is worthwhile to repeat that the estimate of the number of GBs within each GAP is directly related to the availability of certain data about the number of people living inside the dwellings and the daily production of waste by each dwelling. It serves, also, to know what is the conversion factor of the weight of the SW (expressed in $\mathrm{kg}$ ) in space $\left(\mathrm{m}^{3}\right)$, because this latter value has to be correlated with the capacity of the bins (expressed in $\mathrm{m}^{3}$ ). Obviously, the responsibility to get hold of this input data is a burden to the society, either private or public, responsible of the management of the SW.

\section{Further Work}

The solution described in this article can be benefited by the end users with a training on the job of a few hours. In fact, to make the elaborations about the location and the sizing of the GAPs for varying values of the Distance parameter, it is sufficient to invoke, from inside the PostgreSQL query window, the command:

$$
\text { SELECT solveSWAP (distance); }
$$

where solveSWAP() is the UDF collecting the PL/pgSQL code that implements our two algorithms. Similarly, the processing of the queries listed previously can be invoked by copying their SQL code in the same window.

To entice the persons responsible for the management of municipal SW to use our method, an additional engineering effort remains to be accomplished in order to develop a webGIS interface on top of the adopted software architecture. Through such an interface the decision 
makers can access the services available to them in conditions of total independence from the architectural/technological underlying elements.

\section{References}

[1] M. F. BADRAN, S. M. El-HAGGAR, Optimization of municipal solid waste management in Port Said Egypt. Waste Management 26, 534-545, 2006.

[2] J. Bautista, J. Pereira, Modeling the problem of locating collection areas for urban waste management, an application to the metropolitan area of Barcelona. Omega. The International Journal of Management Science 34, 617-629, 2006.

[3] A. M. Damghani, G. SAVARYPour, E. Zand, R. DEIHIMFARD, Municipal solid waste management in Tehran: Current practices, opportunities and challenges. Waste Management 28, 929-934, 2008.

[4] P. Di FELICE, Integration of spatial and descriptive information to solve the urban waste accumulation problem. 3rd Inter. Conf. on Integrated Information (IC-ININFO), Prague, Czech Republic, Sept. 5-9, 2013. Elsevier, Procedia - Social and Behavioral Sciences pp. 182-188, 2014. DOI information: 10.1016/j.sbspro.2014.07.150.

[5] EEA, Managing municipal solid waste. A review of achievements in 32 European countries. Report by the European Environment Agency. http://www.eea.europa.eu/publications/m naging-municipal-solid-waste (Retrieved on June, 2013).

[6] R. Felix, J. Garcia-Vega, Quality of Life in Mexico: A Formative Measurement Approach. Applied Research Quality Life, 7:223-238, 2012. DOI 10.1007/s11482-011-9164-4.

[7] G. Ghiani, D. Laganà, E. Manni, C. Triki, Capacitated location of collection sites in an urban waste management system. Waste Management, 32, 1291-1296, 2012.

[8] D. Hoornweg, P. BhadA-Tata, What a waste: A Global Review of Solid Waste Management. Urban Development \& Local Government Unit, World Bank, Washington, DC 20433 USA, 2012. www . worldbank . org/urban

[9] S. Lebersorger, P. BeIGL, Municipal solid waste generation in municipalities: Quantifying impacts of household structure, commercial waste and domestic fuel. Waste Management, 31, 1907-1915, 2011.

[10] M. MiYAZAKI, T. IMATOH, H. Une, The treatment of infectious waste arising from home health and medical care services: Present situation in Japan. Waste Management, 27, 130-134, 2007.
[11] OBRA, Official Bulletin of Regione Abruzzo - Speciale Ambiente n.25, 15 April 2011 http://bura.regione.abruzzo.it/2011/Spe ciale_25_15_04.pdf (Retrieved on June 2013).

[12] L. Parrot, J. Sotamenou, B. K. Dia, Municipal solid waste management in Africa: Strategies and livelihoods in Yaoundé, Cameroon. Waste Management, 29, 986-995, 2009.

[13] C. S. ReVElle, H. A. Eiselt, Location analysis: a synthesis and survey. European Journal of Operational Research, 165, 1-19, 2005.

[14] G. Tchobanoglous, H. Theisen, S. Vigil, Integrated Solid Waste Management. McGraw-Hill, New York, 2005.

[15] L. TRALhÃO, J COUTINHO-RodRIGUES, L. AlÇADAALMEIDA, A multiobjective modeling approach to locate multi-compartment containers for urbansorted waste. Waste Management, 30, 2418-2429, 2010.

[16] UN-HABITAT, Solid waste management in the world's cities. United Nations Human Settlements Programme, 2010.

[17] US EPA. (2010). Municipal Solid Waste Generation, Recycling, and Disposal in the United States. United States Environmental Protection Agency. http://www .epa.gov/osw/nonhaz/municipal /pubs/msw_2010_factsheet.pdf. EPA-530-F11-005, November 2011. (Retrieved on June 2013).

[18] H. ZIA, V. DEVADAS, Urban solid waste management in Kanpur: Opportunities and perspectives. Habitat International, 32, 58-73, 2008.

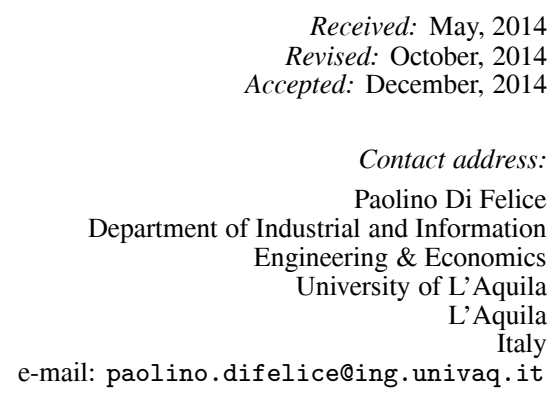

PAOLINO Di FeliCE is Professor of Computer Science at the Department of Industrial and Information Engineering \& Economics of the University of L'Aquila. He has authored or co-authored about 100 articles in international journals, books, and conference proceedings in the areas of programming methodologies, relational and spatial databases. He has also carried out a consistent activity of technological transfer in collaboration with several IT firms. His research has been funded by national and international institutions and carried out in collaboration with researchers of several countries (Italy, Holland, Germany, Canada, and the USA). He has served within national and international committees. In the last years, he is permanently member of the program committee of the International Conference on Integrated Information (IC-ININFO). 